\title{
The Application Strategy of Chinese and Western Traditional Painting Color to Student Education
}

\author{
Haijun Yan * \\ Geely University of China, Dazhou, Sichuan 610000, China.
}

\begin{abstract}
Chromatology in the field of design status is increasingly prominent, through the training of painting chromatology to improve the students' design color expression, creativity to meet the needs of modern development, has become the focus of the discussion. In teaching, chromatology should not only stay in a single surface color, but also be combined with the Chinese and Western cultural painting colors. The structure and concept of color in Chinese and Western art should be systematically studied, and specialized subjects should be adopted to continue the study of subjective color training, so as to try to express one's feelings to the objective world through painting color and create the expression form of traditional painting color in contemporary Chinese and Western art. Combined with the professional training of design ketone, the subjective color and high pressure color aesthetic taste will be gradually formed, and the cultural connotation of design will be enhanced.
\end{abstract}

Keywords: Chinese and Western Traditional Painting; Painting Color; Color Teaching Strategy Art

\section{View of Chinese and western colors}

Through drawing lessons from the Chinese and western color view, seeking rich color language expression way, in a higher artistic level determines the pace of Chinese art, helps us to better grasp the power of modern art innovation and creative source. Chinese and western painting art has similarity.

\subsection{Chinese traditional painting colors}

Traditional Chinese painting pays attention to "according to the type of color", but its color is not the pursuit of the object color sense of reality, neither environmental color, nor completely inherent color, with the painter's great subjective creativity, to express a certain feeling. Such as murals, folk New Year pictures, heavy color scroll paintings, commonly used pure, bright colors cause brilliant, bright tone. The color stimulation of Chinese plastic arts is much calmer.In the attitude towards color, the cultural differences between China and the West doomed the wisdom of color. In the beginning, Chinese art paid much attention to colors. For example, vermilion and cyan were commonly used in painting, so they became red and blue. Reflect people's deep impression and recognition of painting color language. Roughly speaking: the color of Chinese painting before the Tang and Song dynasties is a color, mainly reflected in the fresco, silk painting, lacquer decoration, green landscape painting. For example, green landscape paintings are created to cater to the life situation of the royal family and their relatives. They are resplendent in color and have a strong decorative effect. The paintings of Wang Ximeng, a writer in the Northern Song Dynasty, were still bright and beautiful after a long time. The author organized and allocated colors in the paintings, paying attention to the contrast of the thickness of the colors used. By contrast, the mountain is thick painted green, and the back of the meeting is dyed with powder to increase the sense of thickness. At the same time, light daub is used on the silk to express the water surface, leaving a subtle and elegant temperament.

\subsection{Western painting colors}

Westerners are extremely good at using and presenting colors. The origin of Western art in ancient Greece has been mistaken for a pure world without coloring for a long time. Because many of the architectural relics and sculptures that remain are in the original colors of the materials. But the archaeology of the 20th century shows people the true colors of ancient Greek art. In the researchers' restoration of ancient Greek buildings, bright colors can be seen almost everywhere.

Christian art also attaches great importance to the use of color. Mosaic is an important means of art, decoration in the Byzantine

Copyright (C) 2020 Haijun Yan

doi: 10.18282/l-e.v9i4.1733

This is an open-access article distributed under the terms of the Creative Commons Attribution Non-Commercial License (http://creativecommons.org/licenses/by-nc/4.0/), which permits unrestricted non-commercial use, distribution, and reproduction in any medium, provided the original work is properly cited.

[5]Sun Binghai. Comparison of the consistency between different types of students' emotional self perception and teachers' judgment [J]. China special education. 2010, (02): 11-12.

[6]Jiang Shanye. Concise International Encyclopedia of education curriculum [M]. Beijing: Educational Science Press, $1991: 108$. [7]Shi Zhaoli. Students' classroom power, teacher-student relationship and classroom intergenerational resource allocation [J]. Educational theory and practice. 2018, (11): 22-23.

[8] Shi Zhongying. Knowledge transformation and educational reform [M]. Beijing: Educational Science Press, $2001: 233$. 
church designers in beyond the imitation of nature and true colour is applied, the pursuit of abstract spiritual artistic performance, using a bright gold, bright blue, bright brilliant eye-catching colour such as scarlet, heavy blackish green, make the ends of the earth, and mysterious illusion, to convey the spirit of Christian doctrine ${ }^{[1]}$. Later gothic cathedrals beautiful window glass Mosaic design of revelation, craftsmen with deep red or purple or blue tone, inlaid with a colorful story of the bible, when the sun shines, the story of colour profusion, sparkling, the church also render rich and bright, let a person dizziness, create like god, in the illusion of the mind.

\section{The application of Chinese and western colors in university teaching}

\subsection{Definition of color}

Color is formed by objects with the help of light irradiation, including natural color, light color and environmental color. The so-called inherent color, from the literal view is the inherent color of the object, is actually the object of different color light (light through a prism can be decomposed into red orange yellow green blue purple seven colors) selection of absorption and reflection of the result. The light source and the different environment of the object will make the color of the object change. In the past, people used to paint according to certain colors. The sky was blue, the leaves were green, the flowers were red and so on. The Impressionists, who emerged in the 1870s, noticed that color was determined by changes in light. Monet's "Valley of the Cloz" covered the sky and earth under the reflection of the setting sun with a red light, breaking through the traditional painting method ${ }^{[2]}$. He also painted the same thing from the same point of view - the change of things under different sunlight, such as the haystacks, the poplar trees, the Rouen cathedral landscape and so on. His subtle observation and excellent performance of color shocked the world and earned him the reputation of "color inventor".

\subsection{Color teaching}

Color teaching requires to develop students' thinking and exploration of color as much as possible, and requires students to reflect more personality, imagination and innovative consciousness in content, which is a new kind of thinking. The training of methods and methods of expression is the cultivation of students' comprehensive artistic quality, and the ultimate goal is to serve for artistic design. The training of color perception is the initial stage in color teaching to train students from the imitation of image color to the free expression of color. With the support of color sketching practice, we refine, summarize, comprehend and generate the natural color levels through purpose-oriented and targeted subject training. Professional design concepts and ideas are organically incorporated into the basic color training content to gradually form the cognition and sublimation of subjective colors. Through understanding the color relationship of traditional Chinese folk colors, such as the frescoes of Yongle Palace in Shanxi Province in Yuan Dynasty, we can understand the way of color adornment and intentional change, and grasp the characteristics of decorative color structure. The training of color collection in the course of color design can be carried out through the folk color practice $^{[3]}$. Folk color printing New Year wood-block prints, Dunhuang fresco patterns and folk embroidery pattern colors can be selected for color copying and color transformation, so as to deeply understand the color combination and structure relationship of traditional folk colors. Only in this way can we get rid of the original common standard of realistic color and think inertial, can we rise to the stage of active understanding and creation of color.

\subsection{Study the contrast and blending of colors}

Influenced by the design concept at that time, the current western school of painting basically adopts solid color as the main color, with black, white and gray among the three primary colors of red, yellow and blue, which has a strong visual impact. Western modernist color will adjust color flexibly purely by subjective emotion, the decorative effect of colorific do one's best. Similarly, in Chinese folk New Year wood-block prints, murals, toys, embroidery, facial makeup and other arts, decorative color concept runs through the same. For example, the color effect of Chinese folk wood-block color printing New Year pictures mainly lies in the contrast relationship of colors, including the contrast composition of the whole and part of colors. The bright and full original color system and the imaginative composition form a unique form of beauty filled with rich local flavor. Through students' cognition of the law of western expression color view and Chinese traditional color view, teachers can arrange color decoration training topics, so that students can have a new understanding of objective images, conduct color disintegration and rebuild color order. In this way, students can quickly understand the thinking mode of decorative colors, master the artistic rules of color contrast and harmony, and cultivate their ability to control colors.

The color transmission in the modern plane is the visual expression element of the first sound. The color of the object is required to be liberated from the limited state and have certain emotional factors. The expressive color language of Western PostImpressionism and Yazen School pursues the flat painting method of color, creates the freedom of form, and dare to use the unreal exaggerated color to express the painting in a symbolic way. Such as Van Gogh, Gauguin Klimt and other masters. The golden color that often appears in Van Gogh's works is the painter's typical strong emotional symbol and the most expressive color language factor. Influenced by the Chinese classical philosophical view of "the unity of man and nature", the traditional Chinese color view has the characteristic of giving color according to emotion. For example, Chinese literati painting, light black and white ink landscape reflects the Chinese literati's feelings of detachment.

\subsection{Through the expressive training of color can achieve the effect of color with emotion.}

In modern design, the consistency between external representation and inner spiritual dimension is emphasized. Therefore, in design color training, the extraction of subjective color elements, color collection, induction and reconstruction training are strengthened on the basis of color sketching training, so as to meet the requirements of color modeling ability. The form, means and subject setting of color training should be designed according to the characteristics of professional direction, learning the color emotional expression way of works of Chinese and western art masters such as Van Gogh and Gauguin, and purposeful 


\title{
Stereotype Threat at Work
}

\author{
Wen Zhang* \\ Xi'an International Studies University, School of Chinese Studies, Xi’an 710061, China.
}

\begin{abstract}
Stereotype threat that is an important aspect of diversity management still exists in broader workplace. Many experimental results show that if members of a stereotyped group are brought into an achievement situation where the stereotype can be applied, they often dramatically underperform when they believe their ability in that particular domain is measured. Therefore, eliminating negative stereotypes at work where all employees can perform their true potential, received so much research of different experts. The writers try to suggest some recommendations on how to reduce stereotype threat in working environment so that diversity of human capital really becomes effective competitive weapon.
\end{abstract}

Keywords: FPGA; Human Resources Management; Stereotype Threat; Effective Competitive

\section{Introduction}

In competitive environment, there is a growing awareness of the importance of the human resources management (HRM). As the changing in demand of the economy takes place very quickly and more often. It raises the requirement for each company to introduce new products or services frequently to retain the customers in traditional market and seek for the potential customers in untapped market to survive and growth strategy. It is clear that diversity in human capital is a huge source of innovations and

Copyright (C) 2020 Wen Zhang

doi: 10.18282/1-e.v9i4.1734

This is an open-access article distributed under the terms of the Creative Commons Attribution Non-Commercial License (http://creativecommons.org/licenses/by-nc/4.0/), which permits unrestricted non-commercial use, distribution, and reproduction in any medium, provided the original work is properly cited.

color tone-changing training, color generalization training, color symbolization training, etc. Students are required to change color without deformation to express their true feelings. The ultimate goal is to enable students to express their own emotions and psychology through the use of subjective color language, and to deeply understand the relationship between color expression and spiritual symbol. The fourth stage of color design course teaching is the stage of professional color design and creation. Students can practice the training of color symbolic meaning through color proposition creation. For example, students can feel the image characteristics of the colors of four seasons and taste colors through the creation of color symbolic assignments of "spring, summer, autumn and winter" and "sour, sweet, bitter, hot". The difference between color comprehension and expression is the key and important link of design ${ }^{[4]}$.Western modern art masters such as Picasso, Matisse, Mondrian and other people's color processing techniques are very free, through the feeling of conception and overall arrangement of meaningful color forms. Such as mondrian's paintings inspired the modern design with the originality, mainly in terms of color hue is used to contrast and area of contrast methods, in the "red, yellow, blue composition" series of color processing, the painting on the subjective color tend to be more prominent, the artist according to the need of the picture convey to adjust color piece size and shape, build the whole picture, to establish the color harmonious order.

3. ConclusionDepending on the source of art under the background of Chinese and western color is limitless reserve, in is becoming more and more communication between Chinese and western culture under the background of modern, rich product set the color view of Chinese and western history of modern education plays a profound enlightenment and reference, color of colleges and universities education should take root in Chinese culture, the traditional color of inheriting and carrying forward national culture view, selective absorbing the essence of western performance color view, penetration and applied to the practice of teaching, to create suitable for modern aesthetic form of design and color, achieve the goal of finally for the service.

\section{References}

[1] Xiang Wenjun. Discussion on Color Teaching Strategies in Art Education of Secondary Vocational Schools [J]. Modern Vocational Education, 2016 (17).

[2] LIU Chunyan. Discussion on color teaching strategies in art education of secondary vocational schools [J]. Good Parents, 2017; (73).

[3] Guo Wei. Exploring the Analysis of Color Contrast Teaching Strategies in Art Teaching of Secondary Vocational Schools [J]. Art Education Research, 2017; (22).

[4] Wu Ling. Optimization strategy analysis of color teaching in contemporary secondary vocational art education [J]. Business, 2015; (52). 